\title{
Investigation on the Concept of Local Aesthetic Experience in Chinese Context ${ }^{*}$
}

\author{
WANG Da-qiao \\ Lanzhou University, Gansu, China
}

\begin{abstract}
Aesthetic anthropology is a new paradigm of the modern aesthetic research of China. Professor Wang Jie and his research team put forward the concept of local aesthetic experience in the process of research. The concept is used to summarize and refer to the existing way and existing form of non-western mainstream culture in aesthetic dimension under global context. Local aesthetic experience converges many important problems in the research on aesthetic anthropology.
\end{abstract}

Keywords: Chinese context, local aesthetic experience, aesthetic anthropology

The interdisciplinary research on aesthetics and anthropology behaves as the converse interaction between the two disciplines: On one hand, cultural anthropology uses the theory and methods of aesthetics as the reference, uses the thinking mode of poetics and aesthetics to remold the established paradigm of cultural anthropology and makes itself be suitable for treating the emotional problems of subjective feelings, imagination and experience. In this way, anthropology comes into being. It emphasizes the aesthetics and rhetoricity of anthropology. On the other hand, the discipline of aesthetics uses the theory, materials and methods of anthropology as the reference to research the fields (such as the problem of aesthetic temperament and aesthetic expression of non-western mainstream culture, the problem of aesthetic experience and aesthetic preference of small-sized society or marginal population, the generative mechanism problem of aesthetic interest and aesthetic custom of specific groups or stratums in modern society) which are difficult to be covered by traditional aesthetics. This research paradigm is named as "aesthetic anthropology", "The Anthropology of Aesthetics" or "anthropological aesthetics". The aesthetic anthropology research in Chinese academic world strives to run through the discipline thought of philosophical anthropology, cultural anthropology and aesthetics, research the local aesthetic experience of China and try to establish a new paradigm of modern aesthetic research of China.

\footnotetext{
* Acknowledgements: This paper is a staged achievement of special fund subsidization program of basic scientific research business of central higher education institution of Lanzhou University (program code: 15LZUJBWZY004), and China National Find of Social Sciences "the Research of Fundamental Problems of the Contemporary Aesthetic and Criticism Forms" (15ZDB023).

WANG Da-qiao, male, born in Shuyang, Jiangsu, Doctor of Literature, a professor in School of Literature of Lanzhou University with the research direction of aesthetic anthropology and aesthetics of Marxism.
} 


\section{One}

The strained relation between theory and experience is always a difficult problem which cannot be avoided by aesthetic research. Wang Jie and other Chinese aesthetics researchers have lots of reflection on unceasingly clearing concrete aesthetic contents to adapt to theoretical aesthetic research paradigm. In latest years, the research on aesthetic anthropology is started. It aims at restoring the local aesthetic experience of special ethnic groups. Aesthetic anthropology explains aesthetic experience in the significance of cultural anthropology, which is a new approach of modern aesthetic research. As for aesthetic anthropology, "local aesthetic experience" is an important concept in the academic pursuit of rebuilding aesthetic utterance. It derives from the enlightenment of the concept of "local knowledge" put forward by Geertz. In the appearance process and development process of anthropology, it uses kinds of method and tries to use global insight to integrate the cultural experience of human. In addition, it puts the integrated cultural "experience" of human into the development framework of social evolvement. Universalism is its inherent pursuit. The deep understanding on external culture is limited by the attitude of research on "nationality centralism" and "cultural criticism". The problem of "how to avoid cultural misunderstanding" always confuses the research on anthropology. ${ }^{1}$ In another aspect, the tide of globalization and modernization destroys the locality and national character of culture, which makes culture become homogeneous and inane. It is the academic ideal of anthropology to systematically describe cultural diversity of the whole world. From the interpretive anthropology in the 1960s to the experimental ethnography in post-modernity knowledge horizon, cultural relativism runs through the period. For example, as for the modern history background of American anthropology, we "had better regard interpretive anthropology as the revival and refinement of relativism tradition which was advocated by culture anthropology in the 1920s and 1930s and regarded as the discipline construction foundation” (George E. Marcus, p. 55). Relativism mainly appears with the role of interpretive anthropology and faces the global structure of political and economic power which cannot be denied. "As the embodiment of relativism and interpretive anthropology practice, ethnography challenges global homogenizing idea which originated from western countries and still takes privileged position, common value, social trend of thought which ignores or weakens cultural diversity, and its explanation on reality.” (George E. Marcus, p. 56).

Geertz thinks that it is impossible to remold others' experience world or experience others' experiences in explanation; only the concepts and symbols used in building their own world and explaining the reality can be

\footnotetext{
${ }^{1}$ Among different culture types, the cultural difference and their contradiction determine the complexity and fluidity of emotional structure. "Cultural misreading” is the typical symptom when different culture types mutually encounter. People’s interpretation on kinds of cultural phenomena of customs, concept of value, behavioral pattern, emotional attitude and aesthetic interest is difficult to break away from the influence of their own cultural convention and thinking mode. They can only understand other cultures according to their own cultural habitual nature. "The original 'field of vision' determines its 'no seeing' and 'thorough seeing', determines its selection and cutting on other cultures and then determines its cognition and explanation on them.” (Yue Daiyun, Cultural Differences and Cultural Misreading; Yue Daiyun, Le Buisson, Unicorn and Dragon-the Misreading in Seeking the Universality of Chinese and Western Culture, Preface, page 110, Peking University Press, the version of 1995) Cultural misreading tends to cause two results. Firstly, owing to the influence of ethnocentrism cultural view, intentional or unintentional bias on other cultures can appear. It is the basic point to belittle other cultures. Secondly, other cultures are imagined romantically; they are misread ideally. It is the basic point to adore other cultures with illusion. The "misreading" of demonizing "other cultures" easily breeds "ethnocentrism"; to "romanticize" other cultures contains the criticism on the culture of its own nationality. The cultural misreading of "ethnocentrism" can bring cultural bias, friction and even conflict. The cultural misreading of "cultural criticism" has strong appeal in ideology.
} 
used to understand them. He said that cultural research was not "an experimental science for exploring laws" but "an interpretative science with the significance of exploration". Interpretation is the understanding on "understanding” (Geertz, p. 5). Individual, ego and emotion are difficult to be reflected by traditional ethnography framework. Geertz meticulously investigated the cultural difference and manifestation pattern of the emotion and experience of special ethnic groups. In Cultural Individuals, Time and Behaviors in Bali Society, Geertz talks about "the mind of Bali people". He used individual case interpretation to help to create conceptual research on the culture in ethnography. This can help us to understand the aesthetic dimension of local experience: As for the research on significance, he thinks that "cultural analysis is (or shall be) the speculation on significance. The speculation can be assessed and interpretative conclusions are introduced from good speculations. It is not the mainland for looking for significance; it is not to draw its intangible landscape.” (Geertz, p. 23) In the understanding of Geertz, human's experience cannot be summarized or abstracted. Of course it is not universally suitable. The local knowledge which is based on human's limited and partial living experience has its specialty. So-called "knowledge" is human's experience which is forming following the innovative participation of human. It contacts special experience of ethnic groups; it is not the objective knowledge traversing time and space. The main body of knowledge is the community with correlative relation in specific time and occasions.

Knowledge always comes into being in specific situation and gets defense. Therefore, as for the investigation on knowledge, we shall emphasize the formation of concrete situation conditions of knowledge rather than the universal rules. If traditional anthropology focuses on the common experience of human, interpretive anthropology focuses on the local experience of human. Local knowledge emphasizes the specialty of human's experience and the standpoint of cultural relativism held by human. It has important influence on the formation of the concept of "local aesthetic experience" of aesthetic anthropology.

\section{Two}

Professor Wang Jie regards local aesthetic experience as the core concept of aesthetic anthropology and researches it. His description on the research object of aesthetic anthropology is gradual: "aesthetic experience of China", "aesthetic experience of nationality" and "local aesthetic experience". "Aesthetic experience of China" emphasizes the problem of how to combine the current aesthetics of China with traditional aesthetic resources. The previous and the current can be summarized to be aesthetic experience of China. In the opinion of aesthetic anthropology, "the theoretical foundation of Chinese aesthetics shall be on the basis of the cultural anthropology interpretation on Chinese experience; the specific production mode, living mode and social organization system of China are included; the mental habit and aesthetic custom limited by those are also included; all of those determine the thinking mode, emotional characteristics and expression mode of Chinese people” (Wang Jie, p. 142). Professor Wang Jie thinks that it is possible to establish Chinese aesthetics which is different from western aesthetics if we explore the emotional structure of Chinese culture on the bases of "aesthetic experience of China" and its aesthetic characteristics. "Western aesthetics theory regards visual image as basis and regards 'visual metaphor' as theory framework. When western aesthetics theory has deep crisis, 'Chinese aesthetics' has more and more important theory value and significance. 'Chinese aesthetics' is established on the basis of Chinese culture and Chinese aesthetic experience; 'Chinese aesthetics' regards flowing sound images (such as music, poem, Ci poetry, Yuan verse) as bases and regards 'rhyme' and 'artistic conception' as the core scope and 
representation mechanism. Firstly, 'Chinese aesthetics' is the theoretical summary on abundant and colorful aesthetic experience and artistic experiencing which is based on Chinese culture. Secondly, in certain theory and certain significance, 'Chinese aesthetics' can be popular in the whole world if we theorize and systematize it in the background of modern academic methods and academic ideas. It can become an important academic resource and motivation of its theoretical development in the development tide of diversified world aesthetics." ("The Theoretical Explanation of Chinese Aesthetic Experience and the Development of Literary Aesthetics") "Aesthetic experience of nationality" emphasizes the research on the aesthetics of national art phenomena such as Black-Clothes Zhuang Folk and Naxi Ancient Music.

However, "local aesthetic experience" clearly emphasizes locality and localization. Local aesthetic experience inevitably contradicts globalization. In the trend of the globalization of the society, the local color of culture becomes darker and darker. Standardization and homogenization can be accepted in the field of economy. The field of culture is different from the field of economy and it emphasizes richness and diversity. Local aesthetic experience can offer new experience of success for new culture, cultural industry and aesthetics theory. It can research the new and special aesthetic experience which is different from that of other ethnic groups. "Local aesthetic experience" is a theoretical concept put forward by Professor Wang Jie when researching the aesthetic culture of national minorities. The concept is used to summarize and refer to the existing way and existing form of non-western mainstream culture in aesthetic dimension under global context. He makes a descriptive definition of "local aesthetic experience": "it is a form of perceiving the world with local cultural characters in the significance of anthropology. It includes the form of treating the relationship between human and the nature; it includes the sensate culture of cultural identity and cultural differentiation of the people with different gender, age and stratum; it also includes the different aesthetic significance caused by different perceptive modes and the mode of treating the external matters. Concreteness and particularity are the main features of 'local aesthetic experience'. The basic factors of 'local aesthetic experience' are culture, habitual nature, cultural tradition, language, customs, cognitive pattern, symbol marks etc..." ("Identity Crisis in Local Aesthetic Experience") The main meanings of "local aesthetic experience" include the following aspects: Firstly, local aesthetic experience is the subject of local aesthetic culture in the significance of anthropology. Secondly, specific ethnic groups can get national identity or cultural identity in aesthetic psychology through aesthetic activities. Thirdly, concreteness and particularity are the main features. Fourthly, local aesthetic experience is the perceptual experience in all the cultural activities and cultural cognition of national minorities and the marginal culture groups in small-sized society. From the descriptive definition of local aesthetic experience, we can see the influence of Geertz and the thought of western Marxism anthropology.

In the article of The Identity Crisis of Local Aesthetic Experience, professor Wang Jie regarded Black-Clothes Zhuang Folk in Napo County of Guangxi Province as the individual case and investigated its following period: In the year of 2000, it was "found"; in 2001 and 2002, it was presented in Nanning International Art Festival of Folk Son; in 2004, it was presented in "Fashion Show of Southeast Asia" during the period of Nanning International Art Festival of Folk Son. In addition, he analyzed the phenomenon of "aesthetic experience being torn" presented by the folk songs of national minorities in the condition of globalization and demonstrated the internal relation and contemporary features of "local aesthetic experience" and the arts of national minorities. In the process of modernization, the integral life prospect of the unity and contradiction 
among culture, economy and aesthetics (or art) has the danger of being torn. Culture and economic globalization greatly oppress local aesthetic experience which is difficult to be commensurate. When local aesthetic experience breaks away from the concrete social situation and solidifies itself to be certain cultural symbol, fragmentization becomes its final foreordination. Profound tragedy has been contained in it. Black-Clothes Zhuang Folk in Napo County of Guangxi Province entered Nanning International Art Festival of Folk Son for two times, which can well interpret these. As the culture of Black-Clothes Zhuang Folks who live in it, once folk song becomes the object of "being seen" and "representation", the "sense of fracture" in experience world may appear. Just like that the people who live in tradition do not know tradition. Once tradition is reflected and represented, they have left the tradition. No matter it is "enforcement" or "voluntary", when the "folk songs" of Black-Clothes Zhuang are extracted from concrete life situation and performed on public cultural stage, the integrality of local aesthetic experience may be broken. The problem may not lie in whether folk songs are performed on stage or not; the extracted folk songs alienate the spirit world. Real living mode is made to be "aesthetic illusion" which cannot represent itself; it is "stared" by others. As for "Li Lina"s who make aesthetic illusion, it is easy to understand "harm is enlarged".

Black-Clothes Zhuang ethnic group lives a traditional daily life in good order in mountain. In government's action of cultural development, it was "enforced" to walk under magnesium light. No matter what mental injury it experienced, the improvement of material life in modernization process is obvious. Therefore, it is easy to understand the voluntary behavior in the second Nanning International Art Festival of Folk Son. Professor Wang Jie thinks that Black-Clothes Zhuang Folk joins in public cultural chorus in the encouragement of economic benefit. Tragic efforts exchanged unsuccessful emotional experience, which aggravated the breakage of significance world. "From the efforts of Black-Clothes Zhuang in Nongwen Village, we can see that they firstly placed their hope on the strength of academic voice; then they placed their hope on the economic capital force of merchants. Both of them are failures. Therefore, deep trauma and the crisis in the aspect of cultural identity are caused." (“Identity Crisis in Local Aesthetic Experience”) Black-Clothes Zhuang’s trauma memory of "being abandoned" means a fact which it is unwilling to accept: they drift at the edge of social development. In the process of modernization, local aesthetic experience is dissociated from the fields of economy and culture. Their value world suffers crisis. The estrangement sense of Black-Clothes Zhuang ethnic group strengthens the emotional memory of "being abandoned". In the background of globalization, the contradictory structure of the aesthetic experience of Black-Clothes Zhuang is inevitable actual existence. In the process of modernization, if economic and cultural incidents are the conscious individual or collective incidents which must be experienced by Black-Clothes Zhuang, they have been involved in the torrent of life no matter they are willing or not rather than participating in the whole modern life. Local aesthetic experiences mutually overlap, mingle and organize. This organization surrounds a main body or this organization creates a main body. This main body may be a person or a collective. If the local aesthetic experience of Black-Clothes Zhuang is a self organization, some relatively ordered experiences unceasingly organize the relatively unordered experiences. If modern unordered experiences greatly exceed the experience range of this ethnic group, it may be an effective solution to change the structural mode of local aesthetic experience while comforting their spiritual trauma.

Geertz requires to describe ethnography from the inner view of culture holder. In fact, ethnography is only the cultural experience of one certain ethnic group which can be felt by observers. The experience described by 
observers is different from the cultural experience of the described object. Objective ethnography is impossible in this significance. It may be the valid thinking approach of aesthetic anthropology to describe the individuals in certain culture how to "experience" their cultural experience. Professor Wang Jie successfully changes the habitual concept of Tony and creates the firm relation between local aesthetic experience and esthetic convention. It is a valid approach of solving the identity crisis of Black-Clothes Zhuang to change aesthetic habit or aesthetic convention.

\section{Three}

The locality of aesthetic experience is a basic fact of human's aesthetic activities. The research on local aesthetic experience can loosen the homogeneity of culture in global context. Aiming at the locality feature of aesthetic experience, the query of Chinese aesthetic voice practice on "universal beauty" mainly has two directions to make efforts: the first one is to emphasize the situationality of "beauty"; the second one is to emphasize the local experience of Chinese aesthetics. These two research approaches have large difference from that of "local aesthetic experience" in the field of aesthetic anthropology.

Professor Xiao Ying once thought that the "beauty" in the field of aesthetic anthropology was universal; it mainly explained the universality of human's aesthetic experience; aesthetic culturology considers the concrete value significance and performance characteristics of beauty in different cultural systems (context). "Aesthetic anthropology mainly explores the 'beauty' on the layer of human existence, namely the value and significance connotation of the basic existence relationship between human and the world. On the basis of aesthetic anthropology, aesthetic culturology explores and reveals concrete value significance and performance characteristics of 'beauty' in different cultural systems (context)." (“The 'Beauty' in Human's Context-Reinterpretation on the Concept of 'Beauty"') The theoretical basis of aesthetic anthropology said by Professor Xiao Ying is philosophical anthropology in the significance of Kant. Human has common organism structure, some basic living experience and corresponding basic values. Therefore, cross-cultural aesthetic standard exists. It means that it is the task of "aesthetic culturology" to talk about the social conditions of producing "beauty" in concrete cultural context. Professor Zheng Yuanzhe stands on the discipline horizon of modern Marxism anthropology aesthetics and standards and explains the situationality characteristics of "beauty" from the core problem of art origin. ("Origin of Art and the Situationality of Beauty") In the theoretical framework of Zheng Wen, "local aesthetic experience” gets the possibility of being understood; however, as a concept, "local aesthetic experience" has not been formally discussed. Doctor Li Bo "analyzes the form of the generation of the relationship between aesthetic subject and the aesthetic object in different cultural areas in aesthetic situation through comparing the aesthetic facts in different cultural areas, draws the multidimensional relationship between aesthetics and culture, aesthetics and human, aesthetics and aesthetic situation, and comprehensively researches the complexity of aesthetics" ("Aesthetic Situation and Sense of Beauty-Anthropological Analysis on Sense of Beauty"). Li Bo queries the existence of "the universality of aesthetics". He makes investigation and argumentation from the "ontology" and "epistemology" of aesthetics research to the paradigm transformation of "artistic anthropology". The "aesthetic situations" of Li Bo not only include "anthropology situation" but also include "philosophy" and "psychology" situation. Among these "situations”, “local situations” in anthropology may be weakened. 
In April, 2005, Shanghai Normal University held academic seminar with the topic of "the local experience and world value of Chinese aesthetics”. “'Local experience' is a concept remolded from 'local experience' in anthropology which is regarded as a reference by the organizers of the seminar. The purpose is to emphasize the particularity of the structure and the complexity of the form of Chinese culture and aesthetics. Besides the research on universality, miniature narrative research on concrete Chinese aesthetic problems is advocated." (Zhong Haiyan, "Exploration on New Ideas and New Framework of the Discipline Construction of Chinese Aesthetics") Professor Liu Shilin thinks that "Jiangnan culture and Qilu culture” are two most important local experiences of Chinese culture. Although they touch the concept of local aesthetic experience, "Jiangnan culture and Qilu culture" are regional cultures. The emotional dimensions of their cultural experience have not appeared prominently. Professor Cheng Xiangzhan clearly uses the concept of "local aesthetic experience" to talk about the relationship between it and ecological aesthetics. He thinks that "local aesthetic experience is the concentrated reflection of ecological wisdom; the relationship between the universality and particularity of aesthetic experience can be clearly explained through deeply analyzing the deep structure of aesthetic experience; in this way, a cross-cultural context-aesthetic ecosystem which accords with ecological spirit is established for the research on aesthetics" ("Ecological Wisdom and Local Aesthetic Experience"). He thinks that the previous esthetics theories lack the emphasis on local aesthetic experience, the reason is the lack of ecology awareness and ecology wisdom. However, the "local aesthetic experience" in the horizon of ecological aesthetics theory and the "local aesthetic experience" in aesthetic anthropology have different directivity.

As a puissant word, the usage of experience is extremely complex and fickle. Sometimes people equate experience with sensory perception; sometimes people think that experience contains more contents-memory and imagination behavior; sometimes experience is regarded as the whole content of thought, feeling, desire and consciousness and the total sum of the aspects of psychological or spiritual life. In aesthetic anthropology, "the aesthetic experience in different nationality and region expresses the aesthetic attitude and aesthetic value tendency of the members of the very nationality on realistic life relations. It starts from different aesthetic experience and researches the aesthetic activities and aesthetic laws in different nationalities and regions to reflect the thinking modes and aesthetic mechanism of the people of the very nationality. In this way, the particularity of the aesthetic activities of the nationality can be found. In the condition of globalization, the inheritance and evolution process of the aesthetic convention of national minorities and marginal population is researched; their aesthetic needs, the expression mode of aesthetic needs and their aesthetic communication activities are explored.” (Wang Jie, p. 148) Local aesthetic experience connects the aesthetic habitual nature and emotional structure of national minorities and marginal population. On the basis, the particularity of Chinese aesthetic experience in global context can be introspected.

\section{References}

George E. Marcus (composer) and Wang Mingming (translator). (1998). Anthropology as Cultural Critique-an Experimental Moment in the Human Sciences. SDX Joint Publishing Company.

Geertz (composer), Naran Bilik (translator). (1999). The Interpretation of Cultures. Shanghai People’s Publishing House. Wang Jie. (2002). Aesthetic Illusion and Aesthetic Anthropology. Guangxi Normal University Press.

Wang Jie. (2008). The Theoretical Explanation of Chinese Aesthetic Experience and the Development of Literary Aesthetics. Jiangxi Social Sciences, (2). 
Wang Jie. (2010). Identity Crisis in Local Aesthetic Experience-Taking the Presentation of Black-Clothes Zhuang Folk in Napo County of Guangxi Province in Nanning International Art Festival of Folk Son as the Example. Literature and Art Research, (9).

Xiao Ying. (2003). The "Beauty” in Human's Context-Reinterpretation on the Concept of "Beauty”. Journal of Tsinghua University (Philosophical Social Science Edition), (1).

Zheng Yuanzhe. (1998). Origin of Art and the Situationality of Beauty. Journal of South China Normal University (Social Science Edition), (3).

Li Bo. (2005). Aesthetic Situation and Sense of Beauty_Anthropological Analysis on Sense of Beauty. (doctoral thesis in the major of literature and art of Fudan University).

Zhong Haiyan. (2005). Exploration on New Ideas and New Framework of the Discipline Construction of Chinese Aesthetics-Summary of "the Local Experience and World Value of Chinese Aesthetics" Academic Seminar. Journal of Xinjiang University, (4).

Cheng Xiangzhan. (2005). Ecological Wisdom and Local Aesthetic Experience. Journal of Jiangsu University, (4). 